\title{
METODOLOGIA GEOFÍSICA APLICADA AO ESTUDO ARQUEOLÓGICO DOS SÍTIOS BITTENCOURT E JAMBUAÇU, ESTADO DO PARÁ
}

\author{
Rigler da Costa Aragão ${ }^{1}$, José Gouvêa Luiz² e Paulo Roberto do Canto Lopes ${ }^{3}$ \\ Recebido em 4 agosto, 2009 / Aceito em 16 março, 2010 \\ Received on August 4, 2009 / Accepted on March 16, 2010
}

\begin{abstract}
Magnetic, total count gamma radiation, and Ground Penetrating Radar (GPR) measurements were carried out on two archaeological sites located adjacent to the place where a miner duct will be buried. The aim of the measurements was to indicate the optimal areas for archaeological excavation to find subsurface remains related to ancient communities that lived in the sites. Magnetic measurements showed anomalies that lead to the discovery of a large amount of ceramic fragments and other remains. Gamma radiation allowed discriminating argillaceous from sandy soil, an important result since sandy soil can be correlated to the archaeological layer, where remains are normally found. Ground penetrating radar confirmed the magnetic anomalies and showed several other anomalous features not related to the archaeological remains.
\end{abstract}

Keywords: magnetometry, gamma radiation, Ground Penetration Radar, GPR, archaeology.

RESUMO. Medidas magnéticas, de radiação gama e eletromagnéticas com o Radar de Penetração no Solo (GPR) foram realizadas em dois sítios arqueológicos localizados nas proximidades de uma área destinada à construção de um mineroduto. 0 objetivo das medidas foi identificar locais para escavação arqueológica visando a descoberta de remanescentes de habitantes que povoaram a região em tempos pretéritos, auxiliando nos estudos para recompor a sua história. As medidas magnéticas evidenciaram anomalias que levaram à descoberta de uma grande quantidade de fragmentos cerâmicos e de outros artefatos. As medidas de radiação gama permitiram a discriminação entre solo arenoso e argiloso, o que representa um resultado importante, pois o solo arenoso geralmente é correlacionado à camada de ocupação arqueológica onde são encontrados os remanescentes. 0 Radar de Penetração no Solo confirmou as anomalias magnéticas e mostrou outras feições anômalas não relacionadas aos remanescentes arqueológicos.

Palavras-chave: magnetometria, radiação gama, Radar de Penetração no Solo, GPR, arqueologia.

\footnotetext{
1Programa de Pós-Graduação em Geofísica - UFPA, Caixa Postal 8608, 66075-110 Belém, PA, Brasil. Tel.: (91) 3264-5735; Fax: (91) 3183-1693 - E-mail: rigler_aragao@yahoo.com.br

2Departamento de Geofísica - UFPA, Caixa Postal 8608, 66075-110 Belém, PA, Brasil. Tel.: (91) 3183-1671; Fax: (91) 3183-1609 - E-mail: gouvea@ufpa.br

3 Museu Paraense Emílio Goeldi, Av. Perimetral, 1901, 66040-170 Belém, PA, Brasil. Tel.: (91) 3217-6036; Fax: (91) 3274-0857
} 


\section{INTRODUÇÃo}

A existência de leis de prevenção a impactos ambientais e culturais faz com que projetos de exploração e de utilização de determinadas áreas da união incluam em seu planejamento estudos de impactos ambientais e culturais. Por esse motivo, é comum a solicitação de levantamentos arqueológicos com o objetivo de salvar e resgatar a história e a identidade cultural do local de desenvolvimento dos projetos. Esta é uma medida prevista na legislação brasileira de proteção ao patrimônio arqueológico (Lei 3.924/61, Resolução CONAMA n 01/86, Portaria IPHAN nº 07/88). Neste contexto, foi celebrado um convênio entre o Museu Paraense Emílio Goeldi - MPEG, a Mineração Bauxita Paragominas - Vale e a Fundação Instituto para o Desenvolvimento da Amazônia - FIDESA, com duração estimada para três anos, no qual seria realizada a prospecção e o salvamento arqueológico na área de atuação da Mineração Bauxita Paragominas e no seu entorno. Entre as áreas de estudo do convênio está aquela adjacente ao local onde será enterrado um mineroduto ligando a mina de bauxita localizada em Paragominas-PA e a indústria Alunorte localizada em Barcarena-PA.

No levantamento arqueológico preliminar, a equipe do $\mathrm{Mu}$ seu Paraense Emílio Goeldi, liderada pelo arqueólogo Paulo do Canto Lopes, detectou três prováveis sítios arqueológicos ao longo do percurso planejado para o mineroduto, localizados nos municípios de Barcarena, Abaetetuba e Moju, no estado do Pará.

Com o objetivo de auxiliar a prospecção arqueológica, foi solicitado levantamento geofísico para indicar locais para escavações. No trabalho foram realizadas medidas do campo magnético, medidas com o Radar de Penetração no Solo (GPR) e medidas de radiação gama (cintilometria).

Neste artigo serão apresentados os dados levantados em dois dos sítios identificados: Bittencourt, localizado em Abaetetuba, e Jambuaçu, localizado em Moju.

\section{LOCALIZAÇÃO DA ÁREA DE ESTUDO}

Os sítios arqueológicos Bittencourt e Jambuaçu, investigados no presente trabalho, estão localizados a sudoeste da cidade de Belém, capital do estado do Pará, distando desta cerca de $84 \mathrm{~km}$ (Sítio Bittencourt) e 110 km (Sítio Jambuaçu) por via rodoviária. 0 Sítio Bittencourt está situado no município de Abaetetuba, nas coordenadas 144,15' S-4843,32' W (Fig. 1), e 0 Sítio Jambuaçu nas coordenadas 153,06’ S-48³6,18’ W, no município de Moju (Fig. 1).

A principal via de acesso aos sítios é a rodovia denominada Alça Viária, que se inicia no km 10 da BR-316, no município de Ananindeua, pertencente à região metropolitana de Belém.
A área do Sítio Bittencourt investigada no levantamento geofísico encontra-se dentro de um retângulo de $100 \mathrm{~m} \times 50 \mathrm{~m}$, enquanto a área do Sítio Jambuaçu está limitada por um retângulo de $50 \mathrm{~m} \times 60 \mathrm{~m}$.

\section{METODOLOGIA \\ Medidas do campo magnético}

Medidas do campo magnético terrestre são muito aplicadas na prospecção arqueológica, tanto por fornecerem ótimo resultado, como por serem rápidas e envolver custo baixo (Wynn, 1986a, 1986b; Gibson, 1986; Weymouth, 1986; Gaffney, 2008). Em trabalhos realizados na Amazônia este método tem produzido resultados excelentes, principalmente na llha de Marajó, conforme pode ser verificado em Alves (1979), Alves \& Lourenço (1981), Roosevelt (1991), Barradas et al. (1999) e Bevan \& Roosevelt (2003).

No ambiente da prospecção arqueológica, as anomalias magnéticas podem ser causadas por aquecimento intenso do solo produzido por fogões e fogueiras, pelo revolvimento do solo e pelo enterramento de objetos, entre os quais se destacam, na Amazônia, vasilhas, fragmentos cerâmicos e urnas funerárias elaborados com argila, bem como matéria orgânica (lixo).

As fogueiras mantidas sobre o solo criam um ambiente redutor, que favorece a formação de magnetita (principal mineral responsável pela magnetização dos materiais geológicos), quando quantidades moderadas de ferro estão presentes no solo (Wynn, 1986b; Schmidt, 2007). Por outro lado, os solos perturbados por enterramentos frequentemente tornam-se localmente oxidantes, criando um ambiente que destrói a magnetização presente (Wynn, 1986b) ou pode transformar a magnetita em hematita- $\gamma$, que é um mineral um pouco menos magnético (Schmidt, 2007). Também, a decomposição de matéria orgânica (lixo e restos de madeira), enterrada no solo durante a ocupação humana, pode produzir bactérias anaeróbicas que são capazes de transformar, por redução, o mineral hematita- $\alpha$ (não magnético) em magnetita (Schmidt, 2007). 0 embasamento da aplicação do Método Magnético na pesquisa arqueológica é descrito por Aitken (1961).

Os óxidos de ferro maghemita (hematita- $\gamma$ ) e magnetita, que se encontram disseminados nas argilas, são determinantes para a sua magnetização. Com aquecimento, esses óxidos de ferro tendem a alinhar seus domínios magnéticos de forma que a magnetização resultante tenha a direção do campo magnético terrestre, criando anomalias magnéticas de pequena amplitude.

Neste trabalho, as medidas magnéticas foram realizadas com magnetômetro de precessão de prótons Geometrics, modelo G826, que mede 0 campo total e permite identificar perturbações 


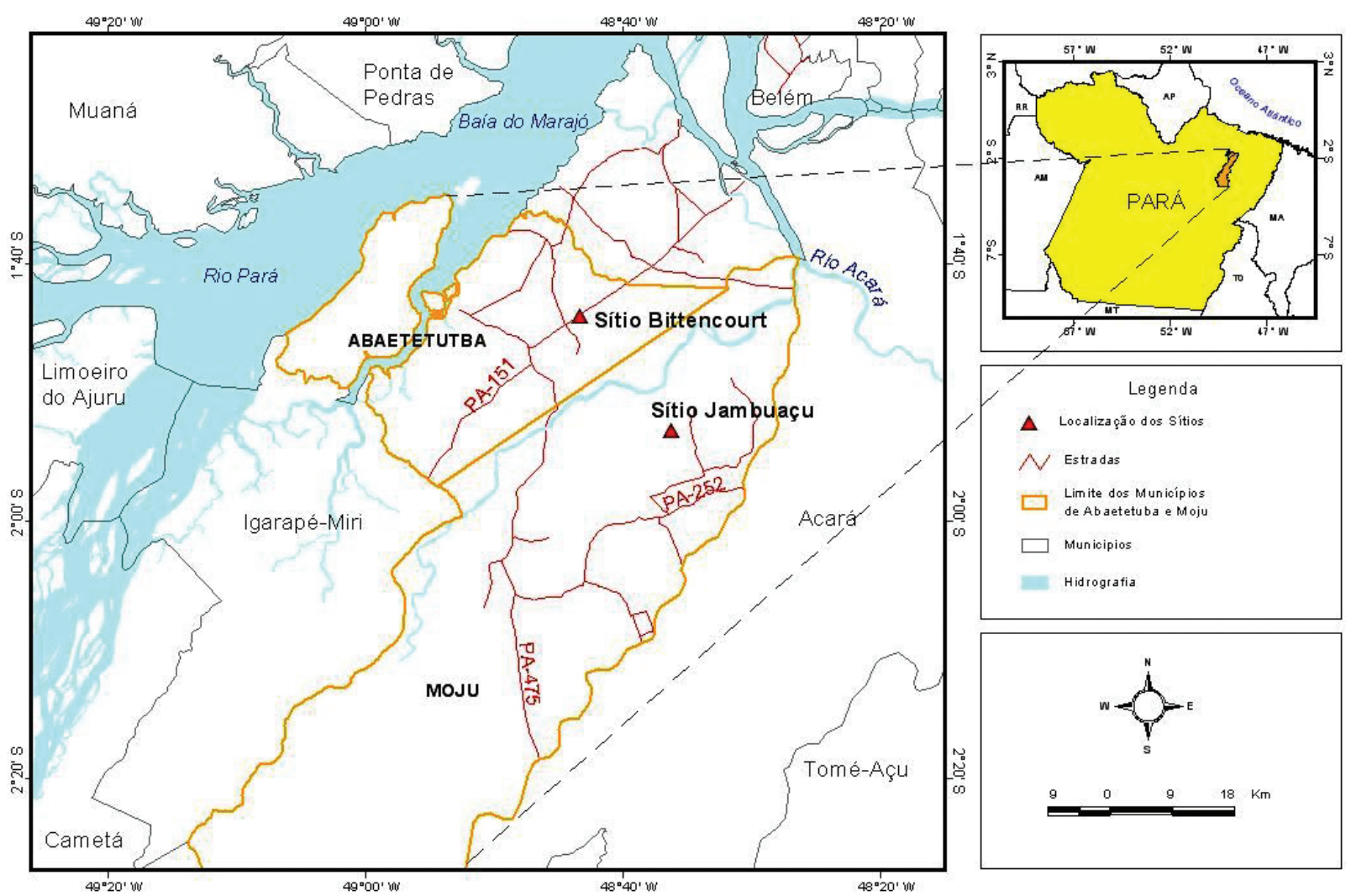

Figura 1 - Mapa de localização dos sítios arqueológicos Bittencourt e Jambuaçu.

no campo magnético da Terra de até $1 \mathrm{nT}$. As medidas foram tomadas em intervalos de $1 \mathrm{~m}$ sobre linhas espaçadas de $5 \mathrm{~m}$ e orientadas na direção oeste-leste. Durante as medidas 0 sensor foi mantido a 0,6 $\mathrm{m}$ da superfície do terreno.

A variação diurna do campo magnético foi controlada por meio da utilização de uma estação base, com retorno à mesma em intervalos de tempo inferiores a 40 minutos.

\section{Medidas com Radar de Penetração no Solo (GPR)}

0 método GPR consiste na irradiação de ondas eletromagnéticas de alta frequência a partir de uma antena transmissora colocada nas proximidades da superfície do terreno, as quais se propagam nos materiais da subsuperfície, sofrendo reflexão, refração e difração. As ondas que retornam à superfície são detectadas na mesma antena transmissora ou em outra antena colocada próximo. 0 tempo decorrido entre 0 instante em que o pulso é irradiado e a detecção do sinal que retorna à superfície, é registrado, permitindo que se estimem as profundidades das interfaces refletoras, desde que seja conhecida a velocidade de propagação das ondas no meio. As interfaces refletoras são definidas sempre que há variações nas propriedades eletromagnéticas do meio (condutividade elétrica, permissividade elétrica e permeabilidade ou susceptibilidade magnética). Detalhes sobre o método podem ser encontrados em Daniels (1996) e Reynolds (1997).

0 GPR tem aplicação na arqueologia por ser um método de investigação não destrutivo, sendo utilizado para pequenas profundidades (menores que $3 \mathrm{~m}$ ). Ele pode ser usado como método principal (Cezar et al., 2001) ou como método complementar ao Método Magnético (Barradas et al., 1999). Neste último caso, contribuindo para a confirmação das anomalias magnéticas e indicando a profundidade das fontes de anomalias magnéticas, dando segurança na demarcação dos locais para escavações e reduzindo os erros causados por falsas anomalias. Outra vantagem do GPR é a sua contribuição para a redução no tempo de exploração, pois as zonas anômalas podem ser visualizadas durante a coleta dos dados.

Feições arqueológicas como solos de ocupação, urnas e dutos enterrados, alicerces de construções e túneis produzem padrões nos registros do GPR bem característicos e podem ser distinguidos dos padrões associados ao material naturalmente depositado durante os processos geológicos. Dentre esses padrões destacam-se as descontinuidades laterais nos refle- 
tores presentes nos registros, causadas normalmente pelo revolvimento do subsolo durante os enterramentos, e as formas hiperbólicas, que podem ser causadas pela presença de urnas, dutos e alicerces de construções.

No presente trabalho, os perfis de GPR foram adquiridos com equipamento GSSI modelo SIR 3000 e antena de $400 \mathrm{MHz}$. As medidas foram realizadas no modo de aquisição por tempo, com 0 controle da distância sendo feito com auxílio de trena e a inserção de marcas no registro a cada $5 \mathrm{~m}$. As linhas de medidas foram espaçadas de $5 \mathrm{~m}$. As medidas magnéticas foram efetuadas sobre as mesmas linhas onde 0 dado GPR foi coletado.

Os registros obtidos com 0 GPR foram processados com auxílio do programa Reflex-Win 4.2 (Sandmeier Software). Foi empregado apenas um processamento básico com os seguintes procedimentos visando melhorar as imagens: (a) redistribuição espacial da amostragem para obtenção de espaçamento uniforme entre as medidas; (b) aplicação de filtro passa alta (dewow); (c) estabelecimento do tempo zero de registro, para obtenção do nível zero de profundidade (posição da superfície do terreno); (d) determinação da velocidade de propagação da onda eletromagnética usando o método da superposição de hipérboles; (e) conversão da escala vertical de tempo em profundidade; (f) aplicação de ganho para compensar a atenuação natural dos sinais; (g) aplicação de filtro passa banda com frequências de corte de $200 \mathrm{MHz}$ e $600 \mathrm{MHz}$; (h) aplicação de filtro de remoção de background; (i) aplicação de filtro de média móvel.

\section{Medidas de radiação gama}

As medidas de radiação gama ou cintilometria são usadas na detecção de radiação proveniente da desintegração natural dos isótopos $U^{238}$ do urânio e $T^{232}$ do tório e suas respectivas famílias, e, ainda, do isótopo $K^{40}$ do potássio, todos eles presentes no solo. A radiação detectada durante as medidas provém, geralmente, de profundidades muito pequenas, que não ultrapassam $0,50 \mathrm{~m}$. Os raios gamas são uma forma de radiação eletromagnética de elevada frequência (superior a $10^{17} \mathrm{~Hz}$ ). Uma descrição detalhada sobre a aplicação das medidas de radiação gama na prospecção geológica pode ser encontrada em Telford et al. (1990).

Esse tipo de medida não é rotineiramente usado em trabalhos de prospecção arqueológica. Ele está sendo usado neste trabaIho numa tentativa pioneira de mapear a camada de ocupação arqueológica denominada terra preta arqueológica (TPA), que é normalmente caracterizada por um solo escuro e que contém o material arqueológico. Na Amazônia, os solos de TPA são frequentemente encontrados sobrepostos a solos de composição argilosa (latossolos argilosos), que são ricos em potássio. Eles também apresentam textura mais arenosa, se mostram mais estruturados e normalmente contêm potássio no seu horizonte mais superior, cuja espessura é inferior a 0,30 m (Kern, 1996). A presença do potássio fornece a possibilidade de se mapeá-los por meio de medidas de radiação gama, uma vez que o mapeamento da camada de TPA é comumente realizado através da amostragem de solo usando tradagem, uma técnica mais demorada e que demanda mais tempo de execução. A Figura 2 mostra uma escavação realizada em um dos sítios investigados neste trabalho onde é possível visualizar uma seção típica da camada arqueológica contendo fragmentos cerâmicos.

Nas áreas aqui investigadas, as medidas foram realizadas com o cintilômetro modelo SPP2 que conta a radiação gama total (sem discriminação do isótopo fonte) incidente em um cristal detector. As medidas foram obtidas a intervalos de $2 \mathrm{~m}$ em todas as linhas utilizadas no levantamento magnético. Durante as medidas o sensor do instrumento foi mantido a uma altura de $0,20 \mathrm{~m}$ da superfície do terreno.

\section{RESULTADOS NO SÍTIO BITTENCOURT Medidas magnéticas}

As medidas magnéticas no Sítio Bittencourt foram realizadas ao longo de 12 linhas numeradas de 5 a 60 . A variação diurna do campo magnético foi controlada utilizando a estação 0 da Linha 30 como estação base, retornando a esta em intervalos de tempo inferiores a 40 minutos. Após a correção da variação diurna, os dados foram representados em mapa de contornos de isovalores do campo total, como mostra a Figura 3. Os valores são relativos ao valor medido na estação base.

0 sítio localiza-se próximo a um mineroduto metálico que causou interferência nas medidas magnéticas e 0 surgimento de uma forte região anômala na parte leste do mapa, a partir da estação 30. Devido a isto, as medidas a leste da estação 30 foram descartadas, pois estas podem mascarar qualquer anomalia magnética proveniente de material cerâmico.

0 mapa da Figura 3 mostra variações do campo total entre $-60 \mathrm{nT}$ a $70 \mathrm{nT}$, as quais incluem anomalias que podem estar relacionadas com o material cerâmico procurado. Essas anomalias aparecem destacadas pelos retângulos identificados pelas letras A a G. As anomalias apresentam as seguintes características: Anomalia A - está orientada na direção NW-SE e ocorre limitada pelas linhas 25 e 30 e as estações 4 e 30 (dois picos negativos são observados nessa anomalia: na estação 27 da Linha 25 e na estação 5 da Linha 30); Anomalia B - é uma anomalia posi- 


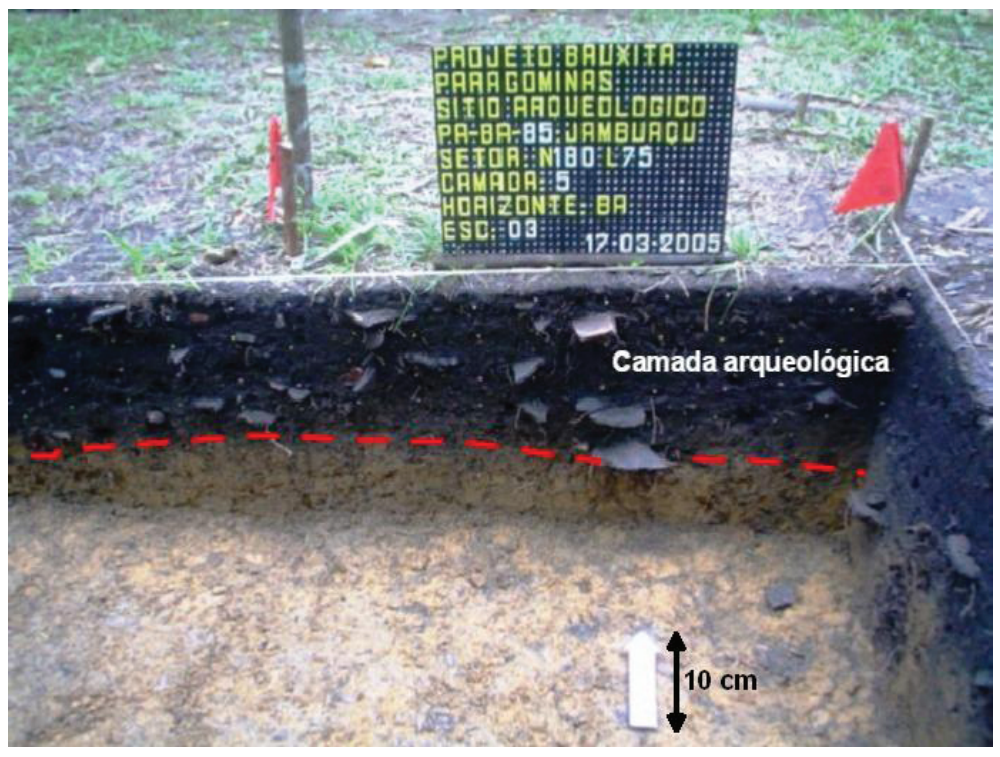

Figura 2 - Escavação mostrando uma seção típica da camada arqueológica contendo fragmentos cerâmicos. A linha vermelha tracejada é o contato entre a camada arqueológica e o solo estéril.
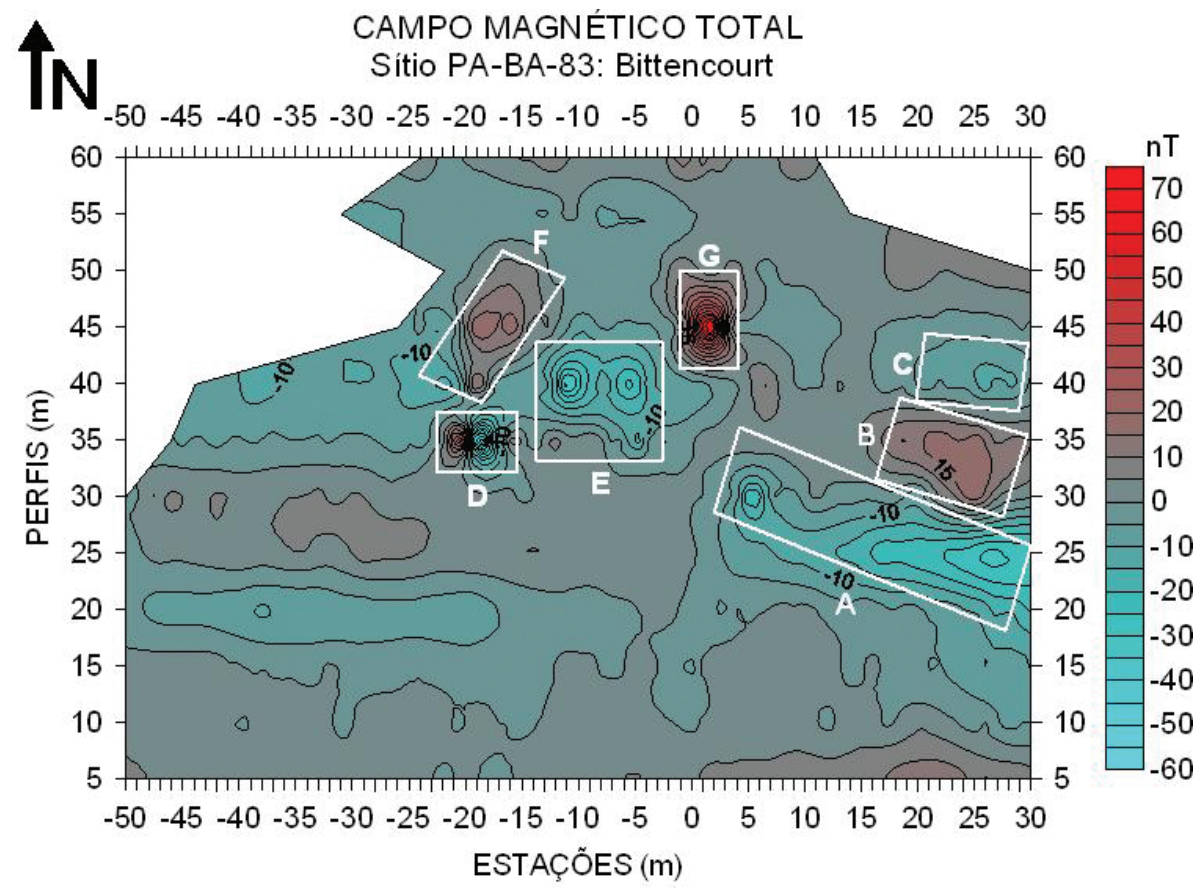

Figura 3 - Mapa magnético de campo total do Sítio Bittencourt. Os retângulos A a G destacam os locais das anomalias magnéticas.

tiva centrada na estação 24 entre as linhas 30 e 35; Anomalia C - anomalia negativa centrada na estação 23 da Linha 40; Anomalia $\mathrm{D}$ - anomalia com pico positivo e pico negativo entre as estações -18 e -21 da Linha 35; Anomalia E - anomalia negativa com picos nas estações - 6 e - 11 da Linha 40; Anomalia F - anomalia positiva alongada na direção NS, com picos estendendo- se da estação -19 da Linha 40 à estação -19 da Linha 45; Anomalia $\mathrm{G}$ - forte anomalia positiva com centro na estação 1 da Linha 45.

Embora as anomalias magnéticas estejam muito bem delineadas no mapa da Figura 3 , foi aplicado um processamento com a finalidade de melhorar ainda mais a sua visualização e melhor 
definir os limites das fontes das anomalias. 0 processamento consistiu no cálculo do sinal analítico (Nabighian, 1972, 1974, 1984; MacLeod et al., 1993), que aparece representado na Figura 4. Esse processamento foi realizado com o programa Oasis Montaj da Geosoft. Os mesmos retângulos usados para destacar as anomalias magnéticas da Figura 3 foram colocados sobre o mapa do sinal analítico para fins de comparação. Observase na Figura 4 que as anomalias ficaram melhor delineadas. As anomalias A, D, E, F e G são bastante destacadas, enquanto as anomalias B e C, evidenciadas como individuais na Figura 3, foram separadas em diversas anomalias menores, sugerindo mais de uma fonte para cada uma delas. Esse é um efeito causado pela operação de derivada segunda, usada no cálculo do sinal analítico, que ressalta anomalias mais rasas.

Todos os locais das anomalias magnéticas foram indicados para escavação.

\section{Medidas cintilométricas}

As medidas cintilométricas foram tomadas a intervalos de $2 \mathrm{~m}$ ao longo de 13 linhas numeradas de 0 a 60 . Os valores medidos estão representados no mapa de isovalores mostrado na Figura 5. As linhas numeradas de 5 a 60 são as mesmas onde foram realizadas as medidas magnéticas.

Os valores de contagem total de radiação medidos na área variaram de 10 a 23 cps. Esses valores refletem basicamente a argilosidade do solo: os valores mais elevados relacionados com o solo essencialmente argiloso e os valores menores ao solo mais arenoso.

Observa-se no mapa da Figura 5 uma distribuição de altos valores no extremo leste da área investigada, entre as estações 47 e 50. Nesse local existe um mineroduto enterrado, sendo os altos valores cintilométricos ali observados provavelmente devido ao material argiloso usado para cobrir e protegê-lo. Essa é, portanto, uma distribuição que reflete um solo não natural. Nos outros locais da área, onde o mapa da Figura 5 mostra valores elevados, eles refletem um solo argiloso.

As análises de solo realizadas em amostras dos sítios em estudo revelaram a associação da camada de ocupação arqueológica com um solo escuro, pouco argiloso. Por esse motivo, a distribuição dos valores cintilométricos mais baixos é importante para 0 seu mapeamento. Ainda não foi possível, entretanto, estabelecer uma boa correlação entre um intervalo de valores cintilométricos e a camada de ocupação arqueológica. Uma primeira aproximação, entretanto, pode ser obtida a partir da Figura 6, que mostra a correlação entre a espessura de TPA (ob- tida através de tradagem) e as medidas de radiação gama ao longo da Linha 0 . Observa-se na figura que quando a espessura de TPA aumenta, a radiação diminui. Isso sugere que, embora tanto a camada de TPA como 0 solo argiloso adjacente contenham potássio, esse elemento é mais abundante no solo argiloso. Também, comparando-se os mapas magnético (Fig. 3) e de sinal analítico (Fig. 4) com o mapa cintilométrico (Fig. 5), observa-se que os locais das anomalias magnéticas coincidem aproximadamente com a zona de ocorrência dos valores menores que $16 \mathrm{cps,}$ exceto no local destacado pelo retângulo G. Ressalta-se, porém, que nem todos os valores menores que 16 cps têm anomalias magnéticas associadas.

\section{Medidas com GPR}

As medidas com GPR na área do Sítio Bittencourt foram realizadas sobre as mesmas linhas do levantamento magnético (linhas 5 a 60).

Em todos os perfis a escala vertical de tempo foi convertida em profundidade usando a velocidade constante de 0,09 m/ns para a propagação da onda; velocidade essa determinada pelo método da superposição de hipérboles disponível no programa Reflex.

Na Figura 7 é mostrada a imagem de GPR obtida entre as estações 14 e 30 da metade leste da Linha 30 dos levantamentos magnético e cintilométrico; local onde, entre as estações 23 e 26 , foi observada a anomalia magnética positiva destacada nas Figuras 3 e 4 pelo retângulo B (anomalia B). Nesse local, observam-se na imagem de radar diversas feições de forma hiperbólica e descontinuidades nas profundidades entre $0,15 \mathrm{~m}$ e 0,40 $\mathrm{m}$. Essas feições aparecem destacadas por uma elipse na imagem de GPR. Uma escavação arqueológica realizada no local evidenciou fragmentos de cerâmica, conforme será mostrado adiante.

Outras feições hiberbólicas também aparecem na imagem da Figura 7, algumas rasas e outras a profundidades superiores a 0,5 m, que não têm nenhuma relação com material cerâmico, conforme foi evidenciado em escavação, podendo ser devidas a concreções ou raízes. Algumas dessas feições aparecem destacadas por círculos na figura.

Os perfis de GPR realizados sobre os locais das outras anomalias magnéticas mostraram feições similares às observadas na Figura 7. Ressalta-se, entretanto, que as feições evidenciadas pelo GPR, quando tomadas isoladamente, não parecem ser suficiente para indicar precisamente os locais onde podem ser encontrados os artefatos arqueológicos, já que outras causas (raízes, concreções, cavidades) produzem feições similares. 


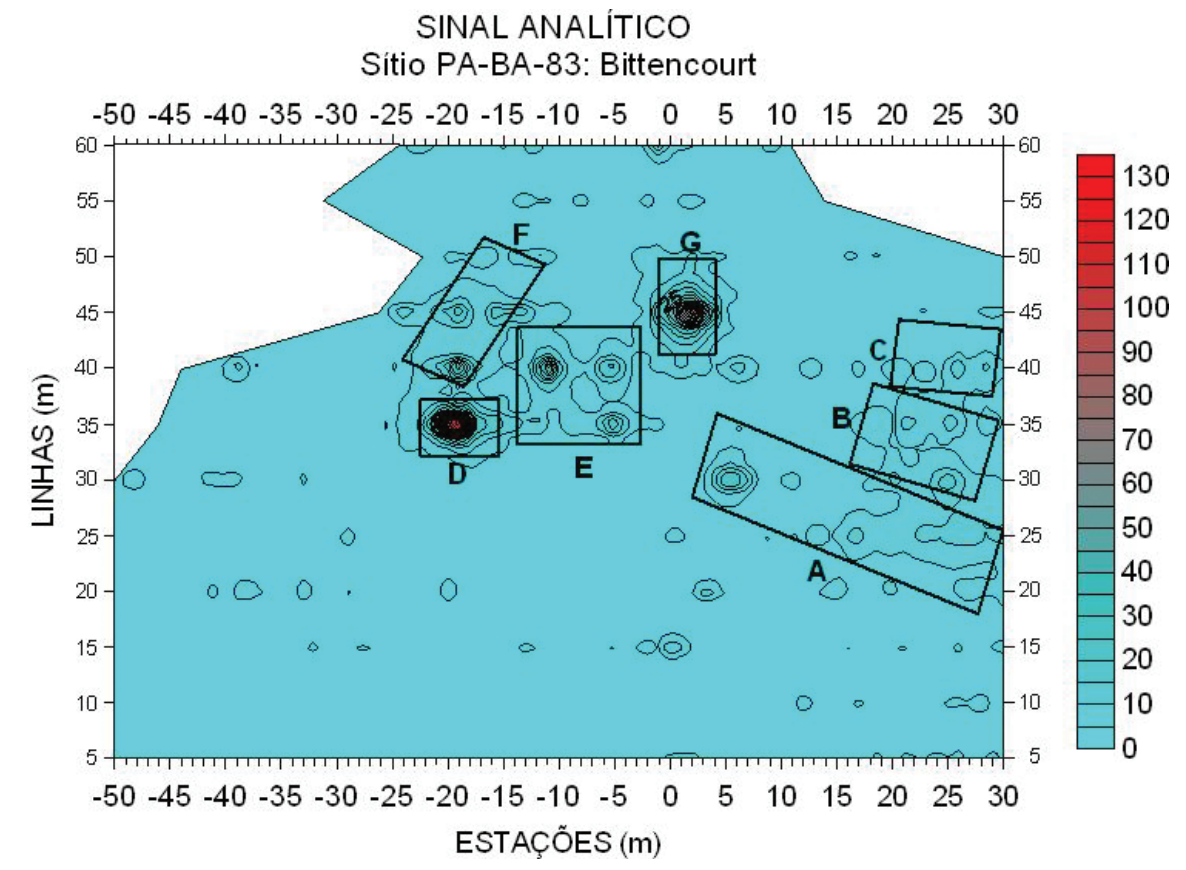

Figura 4 - Sinal analítico para o Sítio Bittencourt. Os retângulos A a $\mathrm{G}$ destacam os locais das anomalias magnéticas.

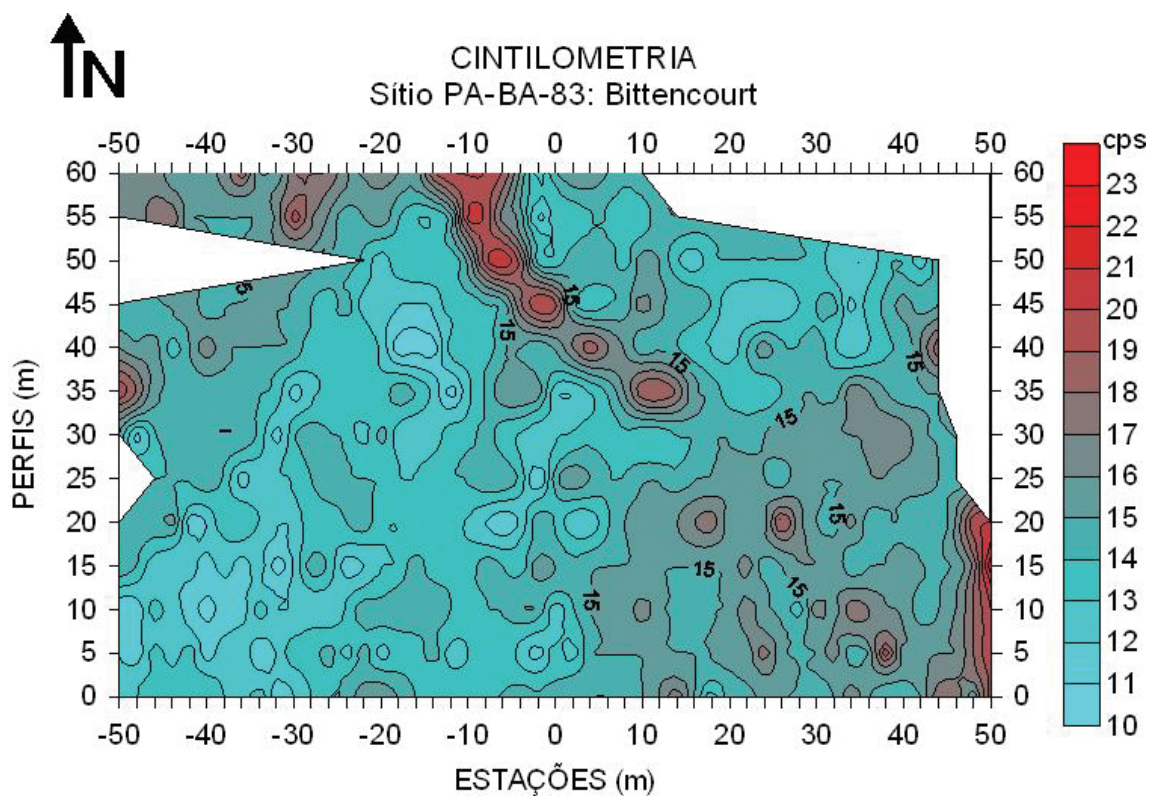

Figura 5 - Mapa de radiação gama para o Sítio Bittencourt.

\section{Escavações arqueológicas}

No Sítio Bittencourt as escavações revelaram fragmentos de cerâmica, faiança, argila queimada, carvão e artefatos de ferro. De acordo com Lopes (2005a), a maior concentração de material arqueológico foi encontrada na escavação de número 6, exe- cutada no local da anomalia magnética B evidenciada nas Figuras 3 e 4 . Nessa escavação foram encontrados sete cachimbos de cerâmica indígena, muitos fragmentos cerâmicos (bordas, bases, alças, louças) e fragmentos de ferro. A escavação 6 foi realizada da estação 20 à estação 30 da Linha 30, sendo também estendida para a Linha 35. Parte da escavação é mos- 


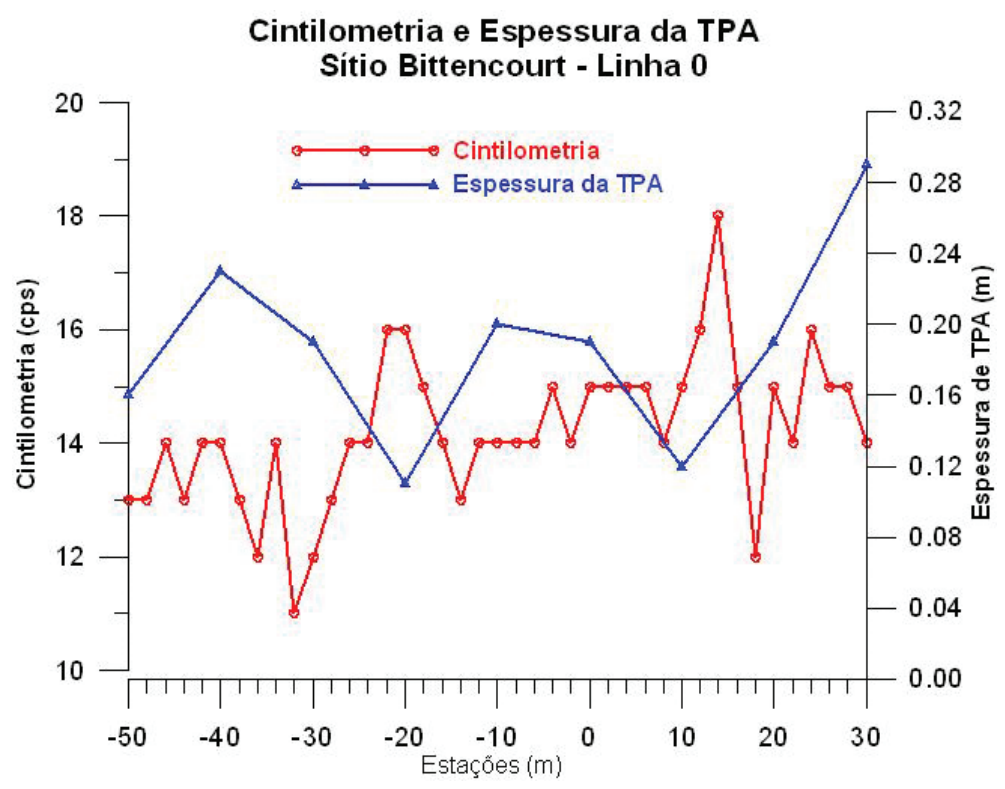

Figura 6 - Correlação entre a espessura da camada de TPA e radiação gama medida ao longo da Linha 0 no Sítio Bittencourt.

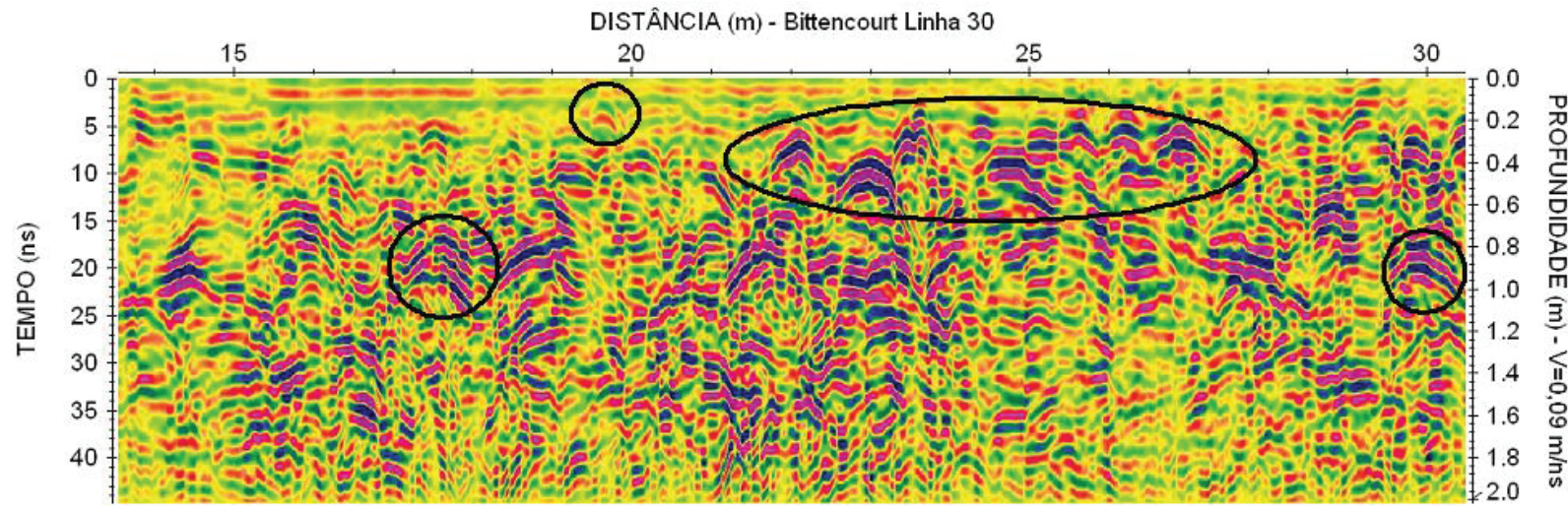

Figura 7 - Imagem de radar obtida entre as estações 14 e 30 da metade leste da Linha 30 do Sítio Bittencourt. A elipse destaca feições nos registros do GPR que foram provavelmente causadas por material arqueológico. Os círculos destacam feições não associadas a material arqueológico.

trada na Figura 8A. A escavação de número 7 , executada no local da anomalia magnética $C$ é mostrada na Figura 8B. As outras escavações que foram abertas nos locais das demais anomalias magnéticas também encontraram material cerâmico, porém em menor concentração em comparação ao encontrado na escavação 6 (Lopes, 2005a).

\section{RESULTADOS NO SÍTIO JAMBUAÇU Medidas magnéticas}

No Sítio Jambuaçu, as medidas magnéticas foram realizadas em 13 linhas de direção oeste-leste, numeradas de 0 a 60 . As medidas foram tomadas apenas na porção da área a oeste de uma linha base de direção norte-sul, que passa na estação 0 das linhas de medida. Esse procedimento foi adotado porque a leste da referida linha base encontra-se um mineroduto metálico, que interferiria nas medidas.

Para controle da variação diurna do campo, a estação 50 da Linha 30 foi tomada como estação base, com retorno a ela em intervalos de tempo inferiores a 30 minutos. Os dados medidos, corrigidos da variação diurna, estão representados no mapa de contornos de isovalores do campo total na Figura 9. Os valores representados são relativos ao valor medido na estação base.

Observa-se no mapa que na região compreendida entre as linhas 45 e 60 ocorre uma série de anomalias com amplitudes variando entre $-25 \mathrm{nT}$ e $75 \mathrm{nT}$, que podem estar relacionadas 

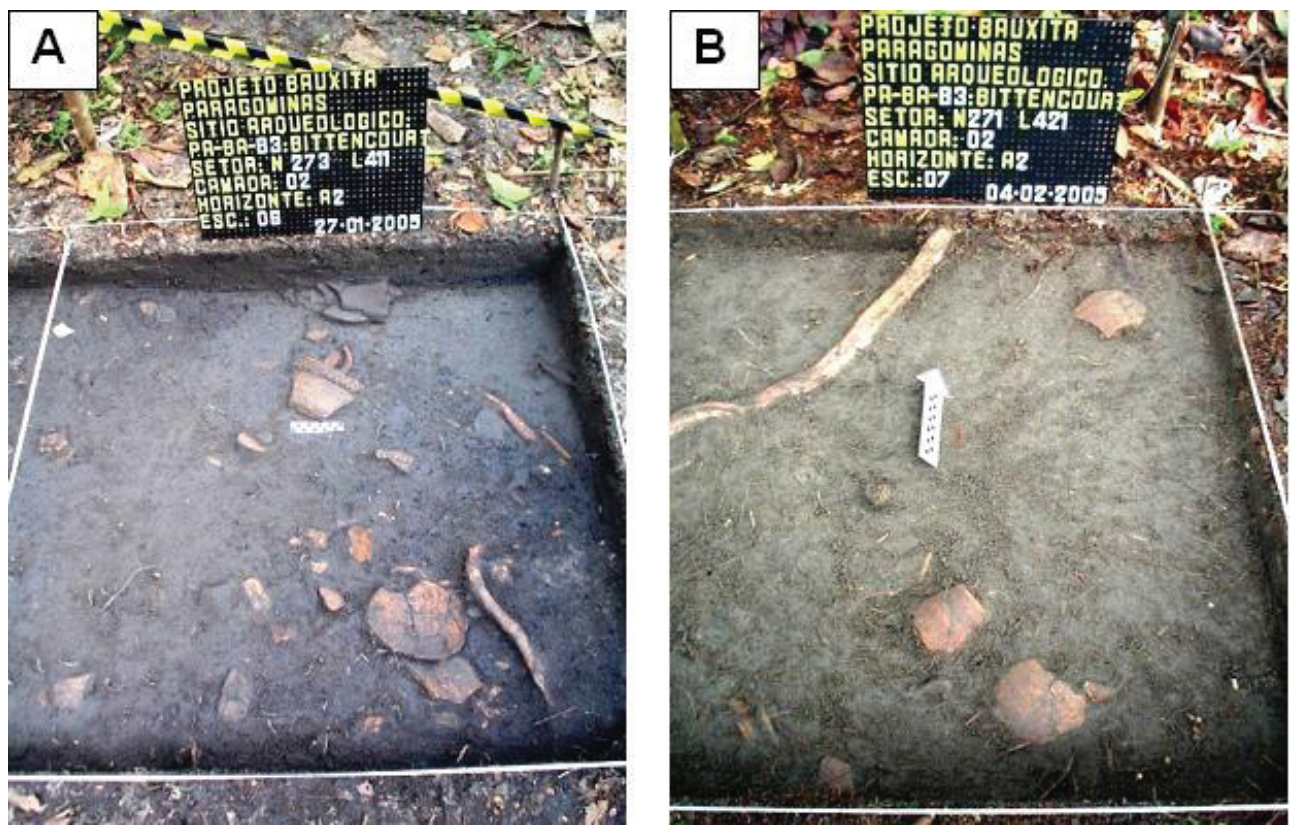

Figura 8 - Parte de escavações arqueológicas realizadas no Sítio Bittencourt mostrando fragmentos cerâmicos; (A) escavação 6 , executada no local da anomalia magnética B; (B) escavação 7 , executada no local da anomalia magnética C.

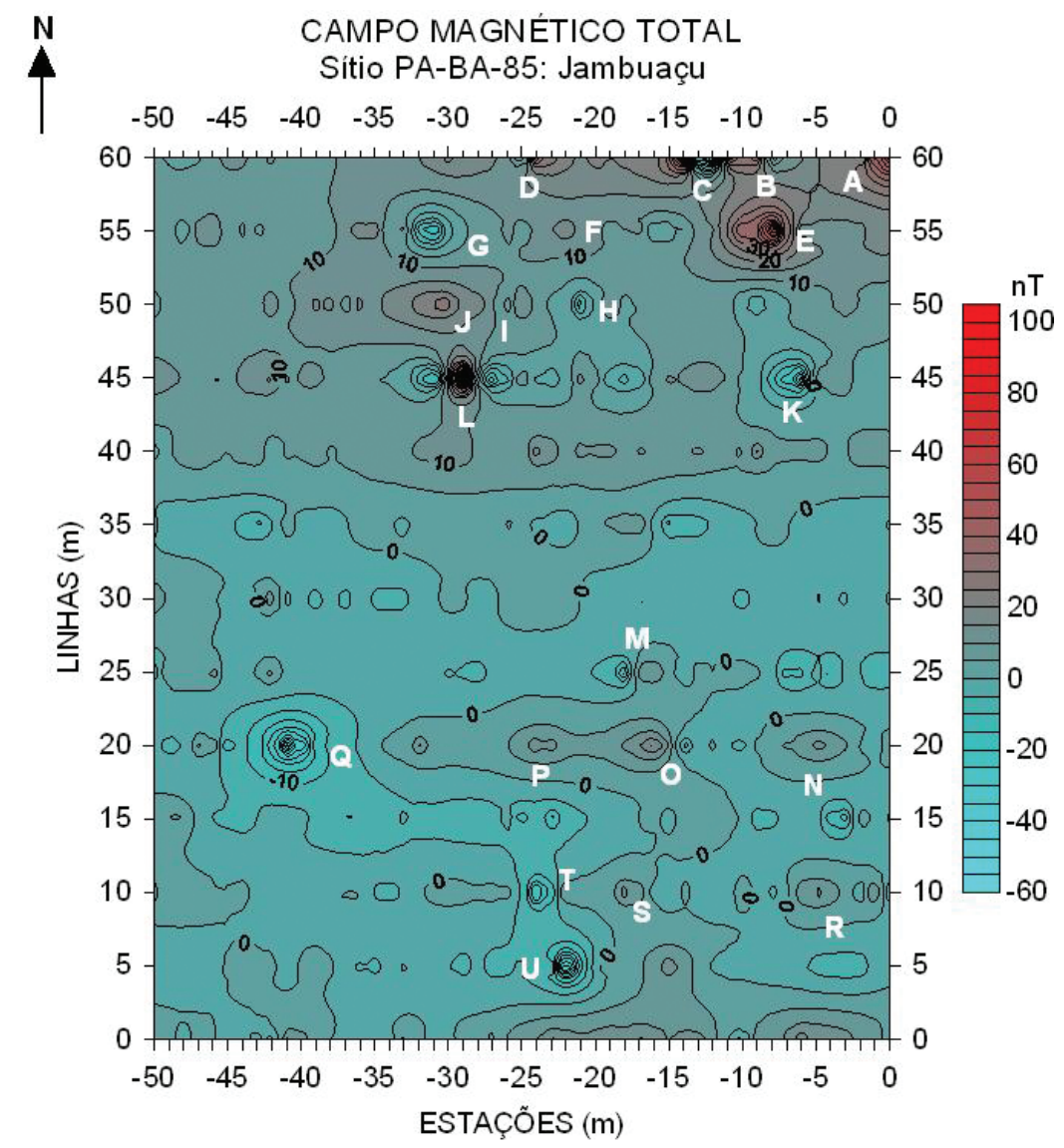

Figura 9 - Mapa magnético de campo total do Sítio Jambuaçu. As letras A a U indicam locais de anomalias magnéticas. 
a material cerâmico. Os centros dessas anomalias encontramse localizados nas estações 0 e -8 (anomalias A e B), entre as estações -11 e -15 (anomalia C) e entre -24 e -25 (anomalia D) da Linha 60; nas estações -8, -22 e -32 da Linha 55 (anomalias $E, F, G$ ); entre as estações -6 e -8 (anomalia K) e entre as estações -26 e -32 (anomalia L) da Linha 45.

Também na região entre as linhas 0 e 25 podem ser observadas anomalias. Nessa segunda região, os centros das anomalias encontram-se nos seguintes locais: entre as estações -16 e -18 da Linha 25 (anomalia M); estações -5, -16, -24 e -41 da Linha 20 (anomalias N, O, P e Q, respectivamente); estações $-5,-18$ e -24 da Linha 10 (anomalias R, S e T); estação -22 da Linha 5 (anomalia U).

As anomalias evidenciadas no mapa da Figura 9 podem ser melhor visualizadas no mapa do sinal analítico mostrado na Figura 10. Observa-se no mapa que, além das anomalias do mapa magnético (Fig. 9), três outras anomalias (denominadas de X1, X2 e X3) podem ser identificadas.

\section{Medidas cintilométricas}

No Sítio Jambuaçu, a amostragem cintilométrica foi feita a intervalos de $2 \mathrm{~m}$ ao longo das mesmas 13 linhas usadas nas medidas magnéticas. Os valores medidos estão representados no mapa de contornos de isovalores mostrado na Figura 11.

Os valores medidos neste sítio variaram de 16 a $43 \mathrm{cps}$, apresentando, portanto, valores mais elevados do que no Sítio Bittencourt, tratado anteriormente.

0 mapa da Figura 11 sugere que o solo no Sítio Jambuaçu é predominantemente argiloso, e com maior argilosidade distribuída na porção sudeste da área. Nessa região foi possível observar a presença de solo laterítico superficial durante a

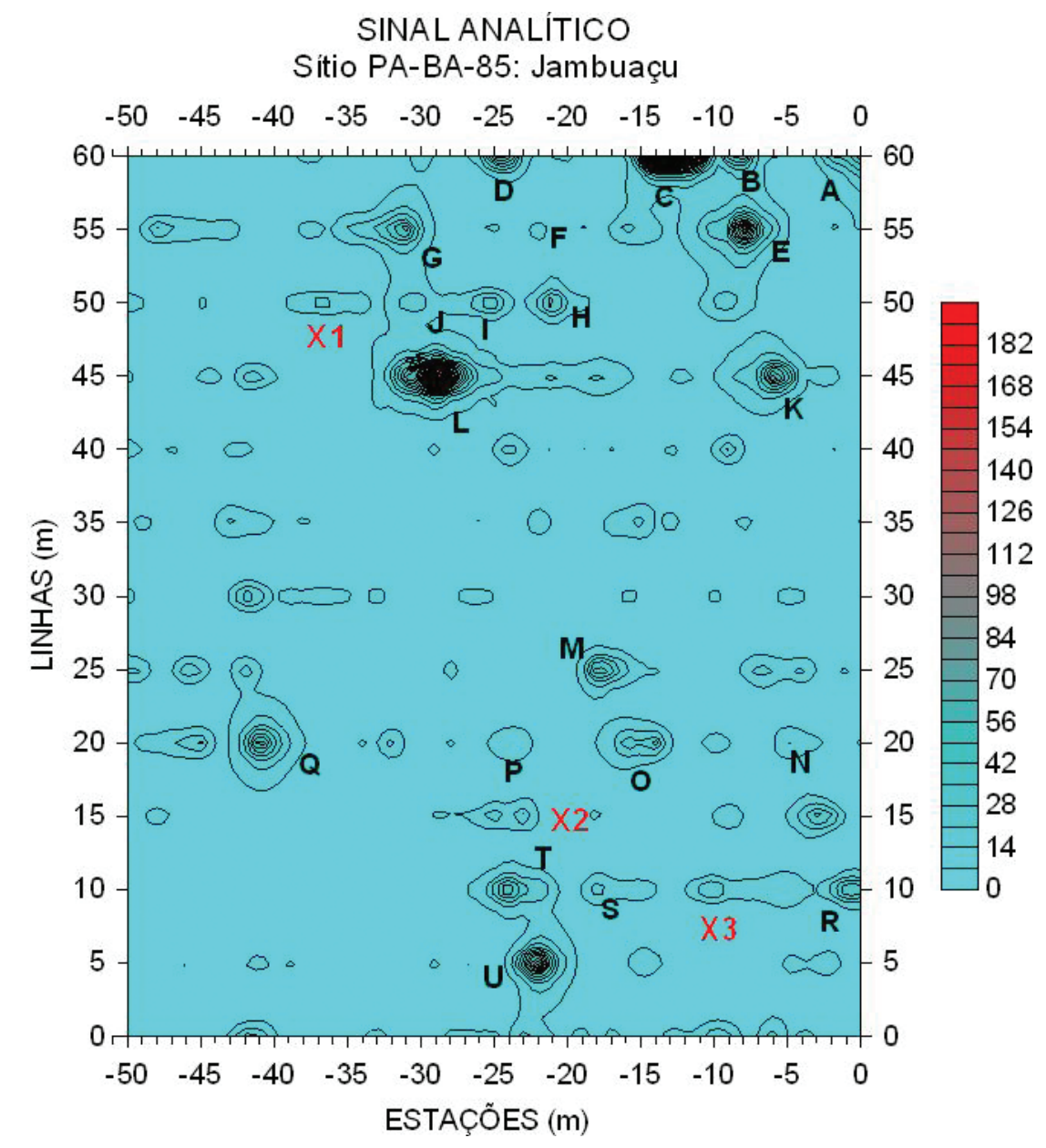

Figura 10 - Sinal analítico para o Sítio Jambuaçu. As letras A a U indicam os locais das anomalias magnéticas evidenciadas no mapa magnético da Figura 9; X1, X2 e X3 são anomalias não evidenciadas no mapa da Figura 9. 


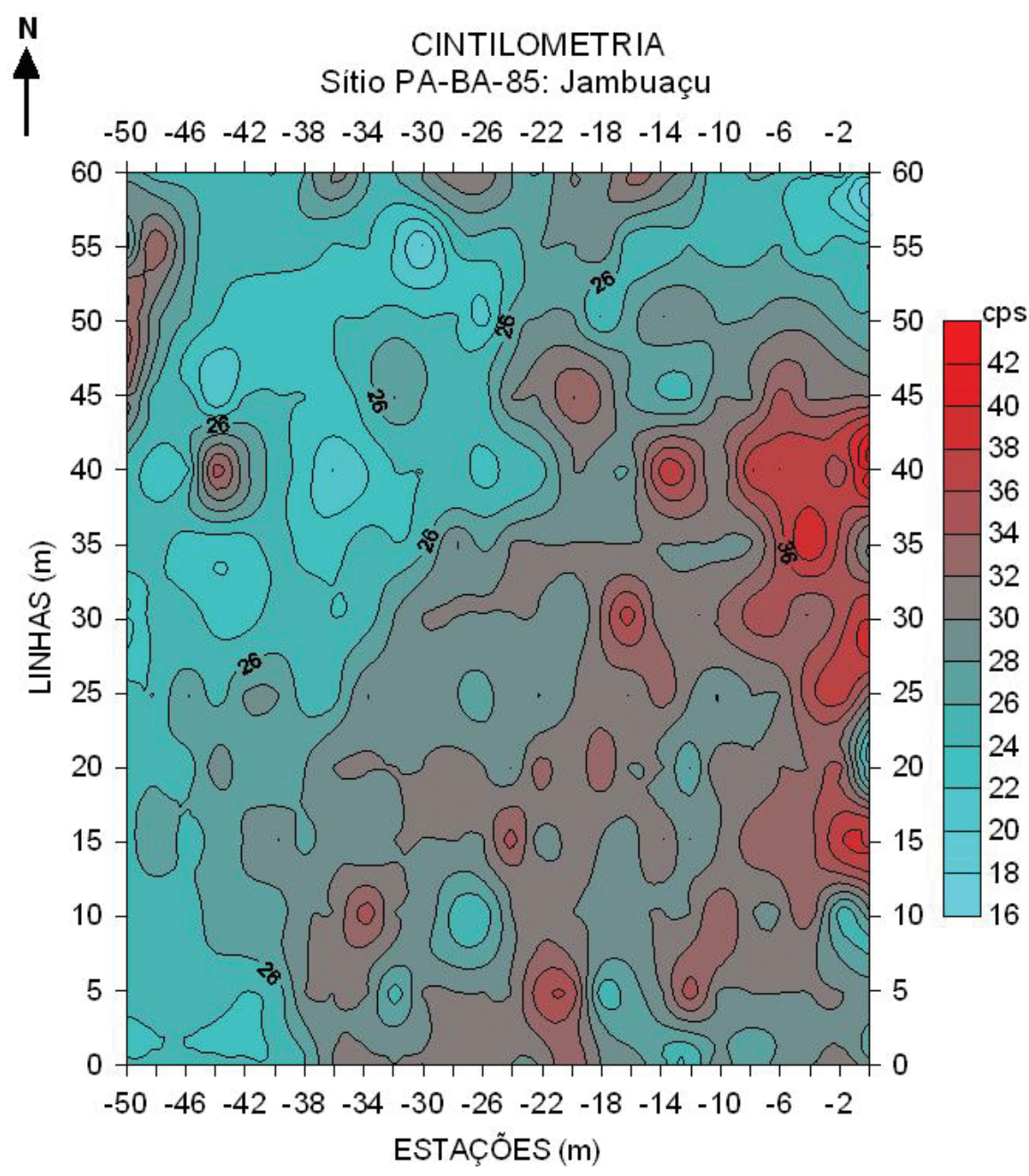

Figura 11 - Mapa de radiação gama para o Sítio Jambuaçu.

tomada das medidas, bem como nas amostras de solo coletas a trado (Lopes, 2005b). Por ocasião do levantamento geofísico foi possível constatar, ainda, que quanto mais escuro era o solo, menores eram os valores cintilométricos.

Comparando-se o mapa cintilométrico com os mapas magnético (Fig. 9) e do sinal analítico (Fig. 10), observa-se uma boa correlação entre as anomalias magnéticas evidenciadas e os valores mais baixos de cintilometria (valores inferiores a 27 cps).

\section{Medidas com GPR}

As medidas com GPR na área do Sítio Jambuaçu foram realizadas sobre as linhas do levantamento magnético, procurando-se cobrir apenas as partes das linhas que apresentaram feições magnéticas anômalas.

Em todos os perfis, a escala vertical de tempo foi convertida em profundidade usando a velocidade constante de $0,09 \mathrm{~m} / \mathrm{ns}$ para a propagação da onda. A velocidade foi estimada a partir do método da superposição de hipérboles.

A Figura 12 mostra a imagem obtida entre as estações 0 e -35 da Linha 60, onde foram detectadas as anomalias magnéticas A, B, C e D (Figs. 9 e 10). Os retângulos representados na imagem indicam os locais das anomalias magnéticas. Observase que nesses locais os registros de GPR mostram feições hiperbólicas, ondulações e descontinuidades laterais, que não podem ser consideradas diagnósticas de feições arqueológicas, já que aparecem em outros locais da imagem.

Uma segunda imagem, mostrando 0 intervalo entre as estações -13 e -29 da Linha 55, está representada na Figura 13. 0 retângulo desenhado na imagem destaca o local da fraca anomalia magnética $F$ (Figs. 9 e 10). Nesse local são visíveis duas feições hiperbólicas: uma delas sob a estação -21 e profundidade de $0.30 \mathrm{~m}$ e a outra abaixo da estação -20 e profundidade 


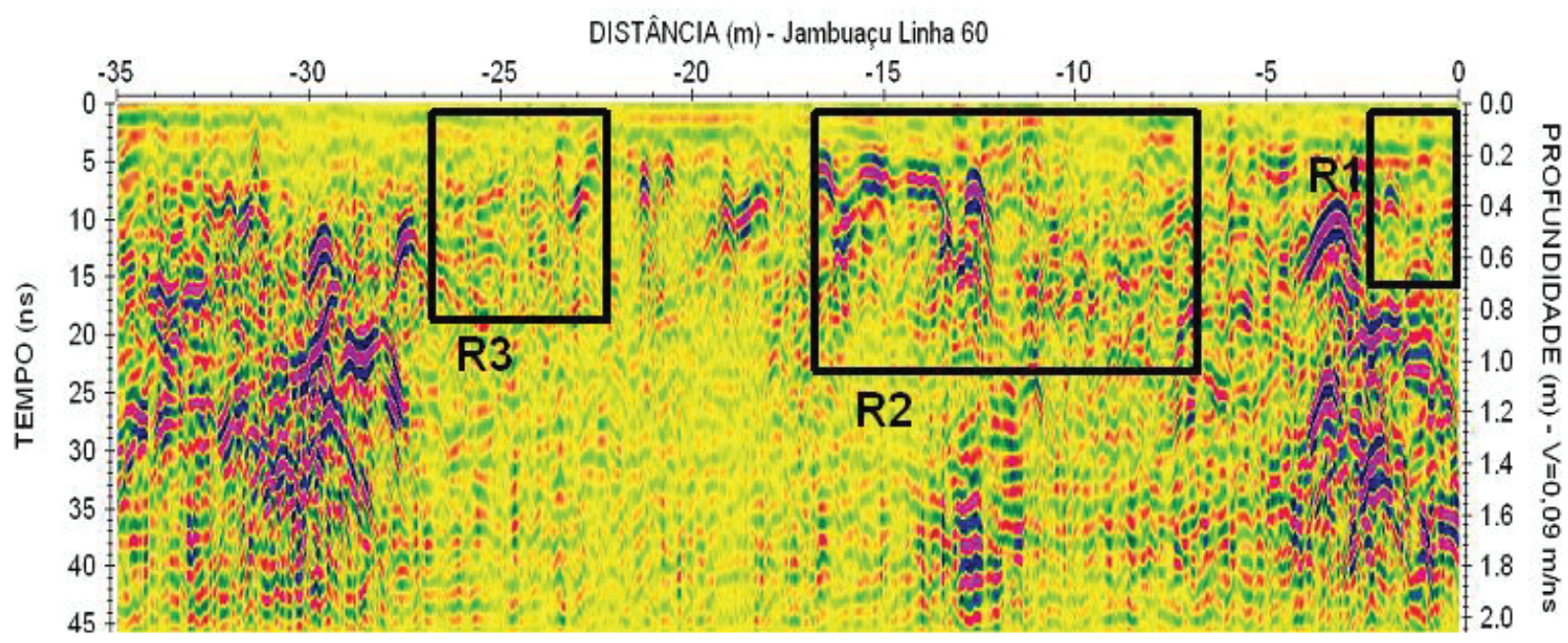

Figura 12 - Imagem de radar obtida entre as estações 0 e -35 da Linha 60 do Sítio Jambuaçu. Os retângulos R1, R2 e R3 destacam feições anômalas registradas nos locais das anomalias magnéticas A, B, C e D evidenciadas nas Figuras 9 e 10.

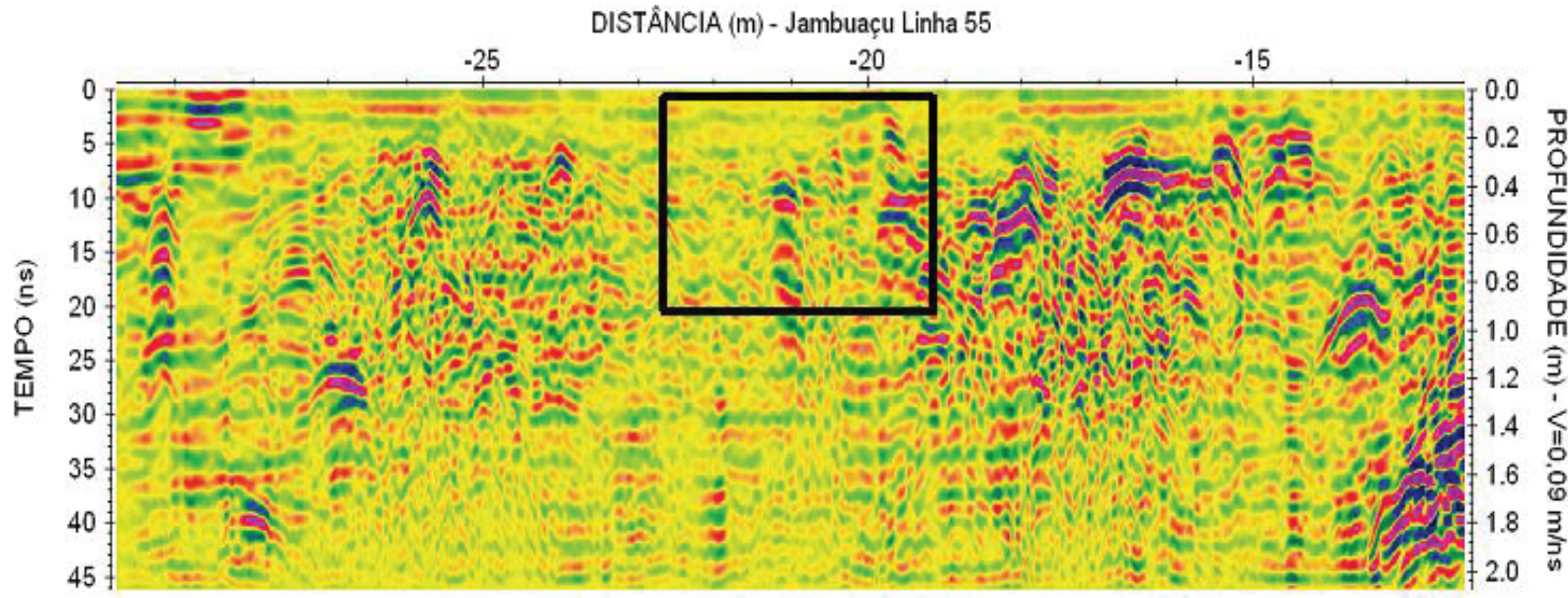

Figura 13 - Imagem de radar obtida entre as estações - 13 e -29 da Linha 55 do Sítio Jambuaçu. 0 retângulo destaca feições anômalas registradas no local da anomalia magnética F evidenciada nas Figuras 9 e 10.

aproximada de $0,15 \mathrm{~m}$. Nas proximidades das feições hiperbólicas ocorrem, ainda, descontinuidades nos registros. Uma escavação realizada no local evidenciou um muro de pedra, conforme será mostrado adiante.

\section{Escavações arqueológicas}

Embora todos os locais marcados como anomalias na Figura 9 tivessem sido recomendados para escavações no Sítio Jambuaçu, somente anomalias localizadas na parte norte da área investigada (entre as linhas 45 e 60 ) foram escavadas. A razão disso foi a região entre as linhas 0 a 35 ter sido considerada pertencente à área externa do sítio pela prospecção arqueológica, não interessando, desse modo, para escavação arqueológica (Lopes, 2005b).

Dos locais sugeridos para escavações na região entre as linhas 40 e 60, somente aqueles das anomalias magnéticas B, C, D, F e H propiciaram a descoberta de material arqueológico. Foram resgatados muitos fragmentos cerâmicos, carvão e argila queimada, além de uma estrutura de pedra. Nos locais das fortes anomalias magnéticas $\mathrm{E}, \mathrm{G}, \mathrm{K}$ e L foram encontrados materiais descartados pelos habitantes atuais (lixo, ferro e material de construção), conforme Lopes (2005b).

Na Figura 14 é mostrada a escavação de número 1, realizada no local das anomalias magnéticas B e C. Essa escavação levou 


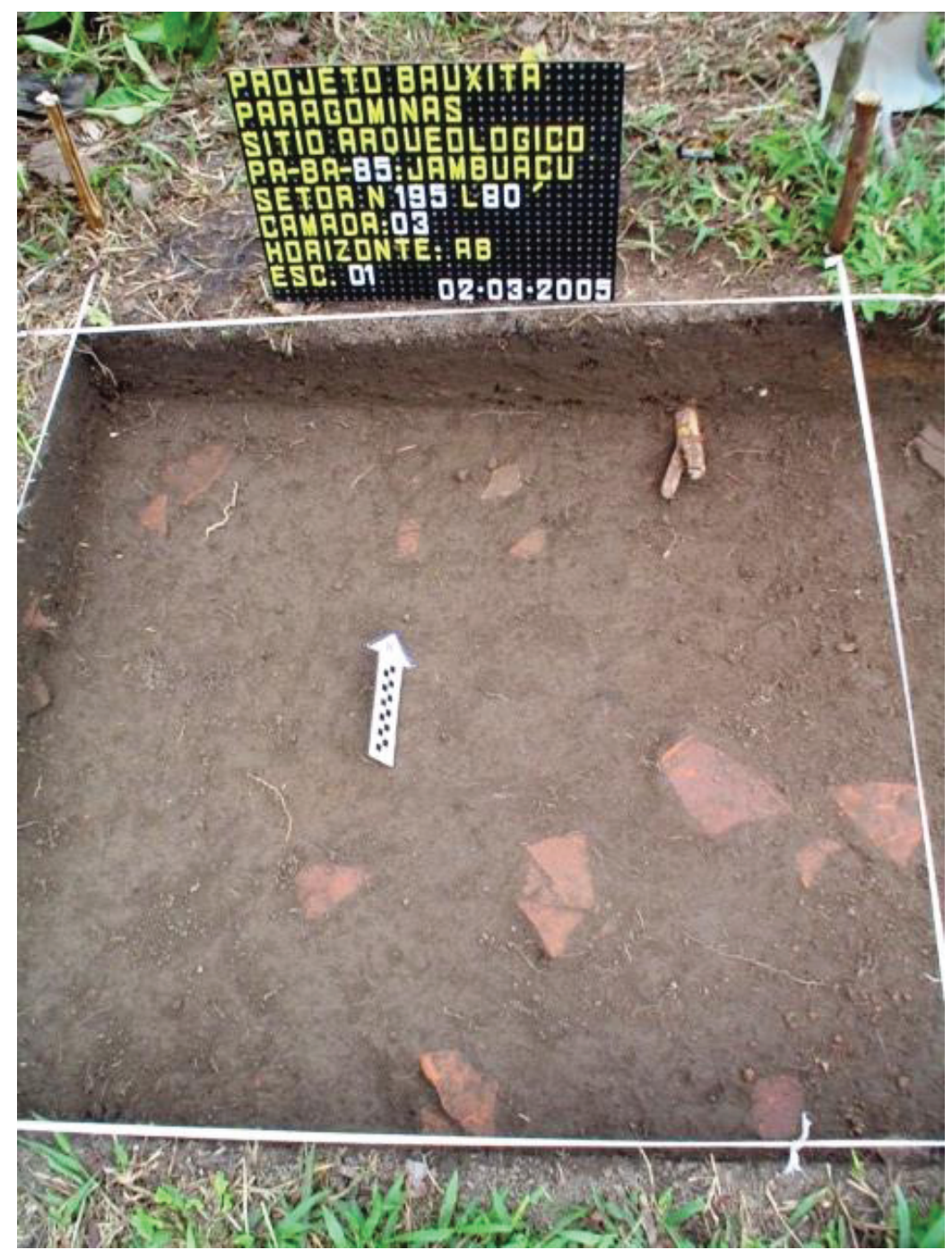

Figura 14 - Parte da escavação 1 executada no Sítio Jambuaçu mostrando fragmentos cerâmicos. 0 local da escavação foi orientado pelas anomalias magnéticas B e C mostradas nas Figuras 9 e 10.

ao resgate de uma vasilha cerâmica indígena, carvão e fragmentos cerâmicos.

A escavação de número 3, realizada no local da anomalia magnética $F$, aparece na Figura 15. Nessa escavação, além de fragmentos cerâmicos foi encontrada uma estrutura de pedra, ainda em análise, que pode ser 0 alicerce de uma antiga construção.

\section{CONCLUSÕES}

As medidas magnéticas realizadas nos sítios Bittencourt e Jambuaçu evidenciaram anomalias que, ao serem checadas por meio de escavações arqueológicas, levaram à descoberta de material importante para que seja estabelecida a história de antigas co- munidades que habitaram a área há tempos atrás. 0 material encontrado, constituído basicamente de cerâmica, será futuramente analisado para que seja estabelecida a sua idade.

Os locais das anomalias magnéticas evidenciadas no mapa de contornos do campo total ficaram mais bem delineados com o mapa do sinal analítico. Com isso, muitas das anomalias isoladas de campo total foram separadas em mais de uma anomalia, sugerindo que elas foram provocadas pela superposição do efeito de mais de uma fonte de menor dimensão e profundidade. Isso é particularmente importante para a prospecção arqueológica, visto que as fontes anômalas são geralmente rasas e de pequena dimensão.

As medidas cintilométricas mostraram valores que podem ser usados para separar as porções mais argilosas das mais arenosas 


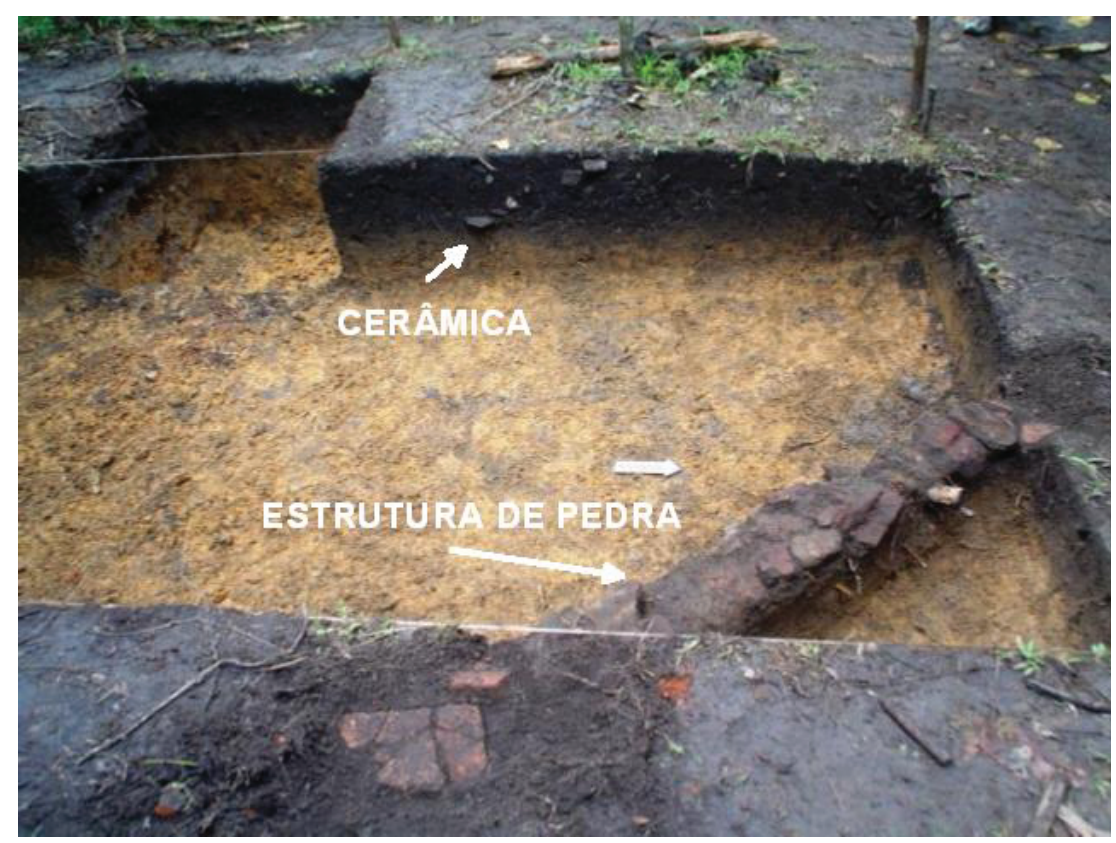

Figura 15 - Parte da escavação 3 executada no Sítio Jambuaçu mostrando uma estrutura de pedra em primeiro plano e fragmentos cerâmicos na parede posterior. 0 local da escavação foi indicado pela anomalia magnética $F$ mostrada nas Figuras 9 e 10.

nos solos das áreas investigadas. Essa separação é importante porque a camada de ocupação arqueológica tem sido identificada na região por sua granulação arenosa e coloração escura, com pouca argilosidade. Os dados de cintilometria sugerem, ainda, que no Sítio Jambuaçu há predominância de solo com uma maior quantidade de argila do que no Sítio Bittencourt.

Um dos objetivos das medidas cintilométricas foi estabelecer uma correlação entre os valores das contagens de radiação gama e o solo da camada de ocupação arqueológica. Embora ainda não se tenha conseguido estabelecer uma boa correlação, as medidas indicaram os locais da área do Sítio Bittencourt onde há valores abaixo de 15 cps como os mais prováveis para a ocorrência do solo de ocupação arqueológica. Na área do Sítio Jambuaçu, por outro lado, os locais mais prováveis correlacionaram com valores abaixo de 27 cps.

As medidas com GPR mostraram diversos padrões anômalos (hipérboles, ondulações, descontinuidades, arqueamentos). Alguns desses padrões apareceram nos mesmos locais onde foram detectadas anomalias magnéticas. Os padrões anômalos, porém não são definitivos na indicação dos locais de escavações, pois muitos deles podem ser devidos a raízes ou a concreções litológicas. É necessário, que esses padrões ocorram associados às anomalias magnéticas, principalmente àquelas evidenciadas pelo sinal analítico, para maior confiabilidade.

\section{AGRADECIMENTOS}

Ao Laboratório de Prospecção Geofísica da UFPA pela disponibilização do equipamento GPR. Ao Serviço Geológico do Brasil (CPRM)/Superintendência do Pará pela disponibilização do magnetômetro e do cintilômetro usados nas medidas. Ao Museu Paraense Emílio Goeldi pela parceria e infraestrutura de campo. Ao Departamento de Geofísica da UFPA pelo fornecimento da infraestrutura computacional. Aos revisores deste artigo pelas sugestões que ajudaram a melhorá-I0. Este estudo foi financiado pela Mineração Bauxita Paragominas - Vale.

\section{REFERÊNCIAS}

AITKEN MJ. 1961. Physics and Archaeology. Interscience, N.Y., 181 pp.

ALVES JJA. 1979. Métodos geofísicos aplicados à arqueologia no estado do Pará. Dissertação de Mestrado em Geofísica. Curso de PósGraduação em Ciências Geofísicas e Geológicas. Universidade Federal do Pará, 55 p.

ALVES JJA \& LOURENÇO JS. 1981. Métodos geofísicos aplicados à arqueologia no estado do Pará. Boletim do Museu Paraense Emílio Goeldi, Série Geologia, 26: 1-52.

BARRADAS JA, SCHAAN DP \& LUIZ JG. 1999. Magnetic and GPR survey to identify archaeological features on Cacoal Site, Anajás River, Marajó 
Island, Pará, Brazil. In: Congr. Internac. SBGf, 6., 1999, Rio de Janeiro. Anais... Rio de Janeiro: SBGf, 1999. CD-ROM.

BEVAN BW \& ROOSEVELT AC. 2003. Geophysical exploration of Guajará, a prehistoric earth mound in Brazil. Geoarchaeology, 18: 287-331.

CEZAR GS, ROCHA PLF, BUARQUE A \& COSTA A. 2001. Two Brazilian archaeological sites investigated by GPR: Serrano and Morro Grande. Journal of Applied Geophysics, 47: 227-240.

DANIELS DJ. 1996. Surface-Penetrating Radar. The Institution of Electrical Engineers, London, 300 pp.

GAFFNEY C. 2008. Detecting trends in the prediction of the buried past: a review of geophysical techniques in archaeology. Archaeometry, 50: 313-336.

GIBSON TH. 1986. Magnetic prospection on prehistoric sites in western Canada. Geophysics, 51: 553-560.

KERN DC. 1996. Geoquímica e pedogeoquímica em sítios arqueológicos com terra preta na Floresta Nacional de Caxiuanã (Portel - PA). Tese de Doutorado. Belém, Universidade Federal do Pará: 119 p.

LOPES PRC. 2005a. Programa de arqueologia preventiva na área do Projeto Bauxita Paragominas: escavação do sítio arqueológico PA-BA83: Bittencourt - Abaetetuba (PA). Relatório de Campo. Belém. Museu Paraense Emílio Goeldi. Área de Arqueologia, 72 p.

LOPES PRC. 2005b. Programa de arqueologia preventiva na área do Projeto Bauxita Paragominas: escavação do sítio arqueológico PA-BA-85: Jambuaçu - Moju (PA). Relatório de Campo. Belém. Museu Paraense Emílio Goeldi. Área de Arqueologia, 72 p.

MACLEOD IN, JONES K \& DAI TF. 1993. 3-D Analytic signal in the interpretation of total magnetic field data at low magnetic latitudes. Exploration Geophysics, 24: 679-688.
NABIGHIAN MN. 1972. The analytic signal of two-dimensional magnetic bodies with polygonal cross-section: Its properties and use for automated anomaly interpretation. Geophysics, 37: 507-517.

NABIGHIAN MN. 1974. Additional comments on the analytic signal of two-dimensional magnetic bodies with polygonal cross-section. Geophysics, 39: 85-92.

NABIGHIAN MN. 1984. Toward a three-dimensional automatic interpretation of potential field data via generalized Hilbert transforms: Fundamental relations. Geophysics, 49: 780-786.

REYNOLDS JM. 1997. An Introduction to Applied and Environmental Geophysics. John Wiley, N.Y., 796 pp.

ROOSEVELT AC. 1991. Moundbuilders of the Amazon: Geophysical Archaeology on Marajo Island, Brazil. Academic Press, San Diego, 495 pp.

SCHMIDT A. 2007. Archaeology, magnetic methods. In: GUBBINS D \& HERRERO-BERVERA E (Eds.). Encyclopedia of geomagnetism and paleomagnetism: 23-31. Encyclopedia of Earth Sciences Series, Heidelberg. Springer, N.Y.

TELFORD WM, GELDART LP \& SHERIFF RE. 1990. Applied Geophysics - Second Edition. Cambridge University Press, N.Y., 770 pp.

WEYMOUTH JW. 1986. Archaeological site surveying program at the University of Nebraska. Geophysics, 51: 538-552.

WYNN JC. 1986a. Archaeological prospection: an introduction to the special issue. Geophysics, 51: 533-537.

WYNN JC. 1986b. A review of geophysical methods used in archaeology. Geoarchaeology, 1: 245-257.

\section{NOTAS SOBRE OS AUTORES}

Rigler da Costa Aragão é graduado em Matemática e mestre em Geofísica pela Universidade Federal do Pará. Cursa o doutorado no Programa de Pós-Graduação em Geofísica da Universidade Federal do Pará.

José Gouvêa Luiz é geólogo formado pela Universidade Federal do Pará, mestre em Geofísica pela Universidade Federal da Bahia e doutor em Geofísica pela Universidade Federal do Pará. Atualmente é Professor Associado da Faculdade de Geofísica da Universidade Federal do Pará, onde desenvolve atividades de ensino e pesquisa. Seu interesse é a Geofísica Aplicada a estudos de prospecção mineral, prospecção de água subterrânea, contaminação do meio ambiente e Arqueologia.

Paulo Roberto do Canto Lopes é graduado em História pela Universidade Federal do Pará e mestre em História pela Pontifícia Universidade Católica do Rio Grande do Sul. É pesquisador visitante do Museu Paraense Emílio Goeldi, onde desenvolve estudos voltados para a Arqueologia Amazônica (pré-colonial e colonial), Arqueologia de Contrato e Arqueologia Ambiental. Presentemente, atua como diretor do Museu Histórico do estado do Pará e é responsável pela área de arqueologia da Secretaria de Estado de Cultura do Pará. 